\title{
Agôn
}

Revue des arts de la scène

Critiques | Saison 2015-2016

\section{Papa doit manger de Marie Ndiaye, Cie Yakka}

\section{Maëline Le Lay}

\section{OpenEdition \\ Journals}

Édition électronique

URL : http://journals.openedition.org/agon/3992

DOI : 10.4000/agon.3992

ISSN : 1961-8581

Éditeur

Association Agôn

\section{Référence électronique}

Maëline Le Lay, «Papa doit manger de Marie Ndiaye, Cie Yakka », Agôn [En ligne], Critiques, mis en ligne le 01 mars 2016, consulté le 23 septembre 2020. URL : http://journals.openedition.org/agon/3992 DOI : https://doi.org/10.4000/agon.3992

Ce document a été généré automatiquement le 23 septembre 2020.

Association Agôn et les auteurs des articles 


\title{
Papa doit manger de Marie Ndiaye, Cie Yakka
}

\author{
Maëline Le Lay
}

\section{RÉFÉRENCE}

Papa doit Manger de Marie Ndiaye, par la Compagnie Yakka, Espace culturel du Bois fleuri à Lormont (métropole bordelaise), le 16 décembre 2015

Dès la scène d'ouverture, le public est plongé dans une atmosphère confinée qui exhale puissamment toute l'angoisse et la cruauté du texte de Marie Ndiaye. Mina, l'enfant, blottie à terre, le visage contracté, les mains crispées sur sa poupée (symbolisant sa sœur Ami), se débat déjà avec ce cauchemar nommé Papa qui, tapi dans l'ombre du bord de scène, tente de la convaincre de le laisser entrer dans l'appartement familial. L'angoisse de l'enfant, interprétée par Malorie Bazin, est immédiatement transmise à la salle qui reçoit en même temps toute la vigueur de l'énergie profondément malsaine de Papa. Encore invisible ce père - incarné par le directeur artistique et metteur en scène de la compagnie Yakka, Namo Kokou Ehah - a une voix inquiétante qui, en étant amplifiée, vibre d'une menace sourde et ne laisse rien augurer de bon: «Papa est revenuuuu !... » susurre-t-il obséquieusement d'une voix grave, basse et feutrée.

2 Si l'écrasante dimension politique de ce texte n'est pas saillante à la lecture, elle est révélée par la mise en scène sobre, poétique et musicale de Namo Kokou Ehah. Nous plongeant dans la sphère privée de la famille et dans l'intimité du couple, la pièce construit une perception de l'autre chez les personnages constamment brouillée par un magma de représentations. Porté par l'écriture dense de Marie Ndiaye dont les dialogues intimes évoquent le genre épistolaire ou le journal intime, le spectacle déroule une tension pesante, comme si les personnages n'en finissaient pas de buter et trébucher sur d'invisibles obstacles.

3 Chacun-e, en effet, ne se parle qu'à lui/elle-même, voire éventuellement au public, mais les personnages ne dialoguent pas. À rebours de la majorité d'entre eux, Maman, 
interprétée par Cécile Delacherie, est caractérisée par une forme de fraîcheur et d'infinie bienveillance. Semblant de prime abord vulnérable à son entourage carnassier, elle se révèle d'une redoutable lucidité. Le faible poids de son ego et son extraordinaire sincérité font d'elle le seul personnage qui puisse dialoguer avec les autres, et donc la seule capable d'amour véritable.

Ce dialogue incessamment empêché et dévié entre les personnages exprime l'impossible rencontre entre des êtres proches (les membres d'une même famille) que leurs réflexes égoïstes de peur et de repli ont refermé sur eux-mêmes. Ces préjugés sont ceux du racisme ordinaire tapi derrière les discours de convenance socialement acceptés : celui de la culpabilité occidentale (le «fardeau de l'homme blanc ») endossée par l'agaçant Zelner interprété avec brio par Philippe Souque, celui de la dette morale de l'Europe envers l'Afrique (que Papa veut faire payer à la France), celui enfin de l'irréductible différence physiologique manifestée par le fantasme de la sexualité débridée et monstrueuse du Noir. Du début à la fin, la rhétorique de la différence scande les propos des personnages: différence entre un «Nous» porté par la voix quasi-unanime de l'infecte famille de Maman et un «Eux» désignant l'ensemble indistinct, repoussant et menaçant, des étrangers et plus précisément, des « Nègres ».

Cette froideur déshumanisante des relations interpersonnelles conduisant aux impasses de l'exclusion et de la peur, la Compagnie Yakka sait la rendre, tant par le jeu des comédiens au plus près de l'égoïsme des personnages qui font tous figure d'antihéros, qu'à travers la scénographie judicieusement pensée pour traduire cet univers d'un pessimisme sans appel. D'un bout à l'autre, la pièce est nimbée d'une atmosphère inquiétante rendue par un subtil entrelacement du mouvement et de la lumière. Les intervalles entre les tableaux sont signifiés classiquement par un assombrissement du plateau, traversé par des personnages marionnettiques, sortes de grandes poupées parées d'une grande jupe cônique, et avançant à petits pas vifs et légers, de façon presque télécommandée. Ces figures sont également signifiées par l'installation ponctuelle sur scène de statues venant illuminer la mine de Maman, qui avoue, dans cette ambiance confinée et empoissée par les propos haineux de sa famille, son « inexplicable » amour pour Papa, envers et contre tout. C'est parce que cet amour est par toute-s jugé insensé qu'il éblouit de son éclat lors de la scène du mariage - à l'acmé du racisme le plus abject - durant laquelle l'intensité lumineuse est maximale. Les ombres chinoises s'y déploient avec grâce et révèlent la nature des personnages : objets déshumanisés, à l'image de leur incapacité à rencontrer l'autre et de leur inadaptation à l'amour.

6 Ébranlant les limites éthiques du dicible par sa stylisation, la mise en scène amplifie la force du texte de Marie Ndiaye. Ce faisant, la compagnie Yakka offre une proposition plus efficace et puissante que bien des théâtres politiques. Elle s'inscrit à rebours d'une dramaturgie "de la pancarte" qui se contente trop souvent d'illustrer, par des allusions accessibles aux seuls initiés, les références historiques relatives à ce qui se joue sur scène. 